\title{
Aus dem Vorwort zur 1. und 2. Auflage.
}

Die vorliegende allgemeine Privatwirtschaftslehre kaufmännischer Unternehmungen - im Gegensatz zur speziellen Betriebslehre des Waren- und Bankhandels, der Industrie und des Verkehrsgewerbes, die vorwiegend handelstechnisch fundiert sein muB — versucht das Typische und Einheitliche der Unternehmungen zusammenfassend darzustellen. Es erschien mir notwendig, für die wichtigsten Grundbegriffe klar umrissene Begriffsbestimmungen zu suchen, die kausalen $\mathrm{Zu}$ sammenhänge zwischen Vermögens-, Kapitalbildung, Ertrag und Umsatz festzustellen. Dabei benutzte ich die Buchhaltung als Mittel zum Zweck; insbesondere die doppelte Buchhaltung ist, richtig gelesen, vorzüglich geeignet, die inneren Beziehungen der in der Unternehmung wirkenden Kräfte aufzuzeigen.

\section{Vorwort zur 3. Auflage.}

Die schwierigen wirtschaftlichen Verhältnisse zur Zeit der Drucklegung zwingen mich zur Beschränkung in den wünschenswerten Erweiterungen der ersten Auflage, die nur als vorläufige Skizzierung des Gegenstandes gedacht war. Neu eingefügt wurden Ausführungen über Schulden und Kredit, die Unternehmungsformen, die Arbeit in der Unternehmung, die Sozialisierung, über Reedereien, den ideellen Wert, das Unternehmungsrisiko, die Zahlungsmethoden, endlich der einleitende Abschnitt und ein Sachregister. Erweitert wurden die Abschnitte über Finanzierung, die Buchführung und die Beispiele für Bilanztypen.

Berlin, Ende Februar 1921.

Leitner. 